\title{
The Economics of Products Liability: A Reaction to McKean
}

\author{
Robert Dorfman†
}

It seems appropriate to begin a discussion of the law and economics of products liability by reminding ourselves that law and economics are such very different disciplines that lawyers and economists are bound to have difficulty in understanding each other's approach to this or any other topic. The trouble is not merely that we have not studied each other's subject; the trouble is that from the outset we approach problems in very different ways and with different purposes in view. I cannot think except with great diffidence about the lawyer's point of view, but I believe it to be pre-eminently practical. Whether the lawyer sits on the bench or stands before it, his business is to make social decisions. In making those decisions he has many things to take into account, and, in particular, he has to apply the standards of ethics and justice and mutual obligation that are inscribed in the law.

The economist, on the other hand, is not concerned with reaching decisions at all. His business is part that of a scientist and part that of a social critic. His task is to describe the way the world operates and if possible to describe it so well and so profoundly that he can infer how the world would operate if conditions were somewhat altered, that is, so he can predict the consequences of following different policies. These predictions are sometimes useful for reaching decisions, but they are not decisions. If a decision is to be reached, one has to add to predictions of different consequences some social scale of values that enables one to tell which set of consequences is to be preferred. As Professor McKean has emphasized, economics itself is not equipped with such a scale of values. So the economist must stop at the point where he can foretell with either weak or great assurance what consequences will flow from alternative measures or policies. The politician, the moralist, the journalist or the lawyer is equipped with the requisite set of values, so that he can make or recommend a decision.

The economist, in short, is preoccupied with descriptions and predictions, the lawyer with legal and equitable decisions. It is no won-

† Professor of Economics, Harvard University. 
der that economists tend to feel that lawyers have inadequate understanding of the facts of life and employ low standards of analytical rigor, while lawyers regard economists as wildly impractical types. We both are right.

In the present instance I suffer from the layman's disability of not really understanding what the legal issues are. I do understand that they have to do with the legal liabilities of firms that manufacture goods and permit them to be placed in the hands of users. Professor McKean has made it clear to me that the law, as applied to this problem, is in the process of change. I gather that no significant new legislation has been enacted but that the courts in recent years have been deciding cases in ways that they would not have decided them some time ago, so that the law is changing and courts are changing it. Now I can see clearly enough that there is a significant social issue here. People occasionally do suffer loss or injury as a consequence of the performance of articles that they have purchased. And it is often a matter of deep human significance to decide who should bear what part of the burden in such cases and to have a policy on which such decisions can be based.

I call that a social problem, rather than a legal one, because it concerns social relationships, although the solution to this problem may be contained in the law. There is an economic problem or question related to this social problem. That is the question of foretelling the effects on various aspects of economic behavior of different possible resolutions of the social problem. Professor McKean insists, and he is correct, that the solution of the economic problem has a bearing on the solution of the social problem, for we should certainly want to resolve the social problem in the best possible way, meaning by this the way in which all the consequences, including importantly the economic ones, are as favorable as possible. That states clearly enough for me how the economist gets into the picture, and what the social and economic questions are. But what I perceive only vaguely is where the legal problem lies.

I have to conjecture what the possible answer to that question may be. One legal problem that I perceive is simply a question of fact: What is the law on the subject at the present time? That is the kind of question, I suppose, that is repeatedly before the courts and that lawyers even outside of court must concern themselves with in order to give helpful advice to their clients. If that is the problem before this conference I clearly am incompetent to contribute and I am not even sure that I am especially interested.

Another possible legal problem can be stated this way: We do not 
have an entirely free hand in resolving the social issue of allocating the risk of using commodities. There are such things as personal rights and property rights that are established under common law, our Constitution, accumulated precedents and so on. There are even real questions as to what legal obligations are practicable and enforceable. So, there is a real question as to the room for choice in resolving the social issue in a way that is consistent with all pertinent aspects of the law. That is a really interesting question, but again I certainly have no illumination to cast upon it. Still a third possible legal question concerns the roles of statutory law and judge-made law. Is the current revision of the law of products liability within or beyond the range of judicial discretion?

None of these conjectures, though, strikes me as very conclusive or insightful, so I still feel that I must approach this paper without clearly comprehending what the legal side of the question is all about.

Under the circumstances, I had better devote myself entirely to the economic question. It will become amply evident in the next few minutes that Professor McKean and I adhere to different schools of economics. Our differences are fundamental and are at bottom methodological. He believes that you can get to the economic essence of a problem by simplifying it in a particular way. I believe in simplification, too, because I recognize that the human mind can deal with only very simple problems, but I am very suspicious of the particular kind of simplification that Professor McKean regards as being most illuminating. It will be recalled from reading Professor McKean's paper that his point of departure for the analysis of the economic consequences of different policies with respect to products liability is to consider the problem in a much simpler world than ours, one in which there are no costs of gaining information or of negotiating contracts or of enforcement. That is a very useful conceptual device for some economic problems. For example, it simplifies the task of analyzing the consequences that may flow from a vastly cheaper source of power, such as nuclear energy. But for other purposes that device can be grossly distorting. For example, it would not be at all helpful to make an economic analysis of the insurance industry in a world in which all sources of ignorance and uncertainty have been assumed away, for the need for insurance would be assumed away also. So, I tend to regard this methodological device with some suspicion. And, in particular, it seems to me that the analysis of products liability is dangerously akin to the analysis of insurance.

But it is Professor McKean's privilege to make these assumptions so long as he follows them to their logical conclusions. And since the 
assumptions of zero costs of information, zero costs of transaction, and zero costs of enforcement have been placed before us, I feel obliged to draw a conclusion from them-namely, that in such a world, the problem of products liability would hardly exist. I must now argue to that conclusion.

First, though, I have to define products liability. The most succinct statement that I could find in the paper is: "The manufacturer would simply be held liable for all injuries occurring with the use of his product, regardless of circumstances." 1 What that definition means, I think, is that if a Cadillac were to ram a Chevrolet, then General Motors would be held responsible for all the resultant damage and injuries, regardless. I cannot believe that the doctrine carried to that extreme has very much future and, therefore, even at some risk of deflecting my remarks from their proper track, I should like to base my discussion on a different definition. My definition is that products liability concerns the responsibility for any adverse consequences that may result from the use of the product and that are attributable to any peculiarities of the product, either of design or of manufacture, which are different from the specifications conventionally and normally expected from commodities of its type. On re-reading that definition, I am sure that any lawyer could have done better, but I think it will suffice as a basis for my discussion. To illustrate my definition, suppose that the head flew off the hammer that a man was using and injured his child. Under my definition there would be no products liability if the hammer were of standard design and were adequately manufactured in the usual way so far as anyone could tell, because everyone knows that hammer heads of the usual type do fly off on occasion. But if this hammer had a peculiar patented method of assembly, and particularly if this novel method of joining was intended to make it safer and was advertised as such, then a question of products liability would arise, and the social question of who should bear the financial costs of the accident would be a live issue.

I have now to discuss the status of the problem of products liability in the sense just proposed and in Professor McKean's world where there are no costs of gaining information or of negotiation or of transacting business. To do so, I shall introduce one distinction which Professor McKean did not make, because it seems to make a difference. The defects that may give rise to products liability are of two sorts: defects of design and defects of manufacture. Defects of design are variations from the normal and standard specifications of the commodity which have been incorporated intentionally in the article

1 McKean text following note 117 . 
sold. The use of a novel method for affixing a hammer head to its handle is an illustration. Defects in manufacture are unintentional variations from normal standard specifications. They arise in the course of manufacture because it is not possible to make any number of articles identical to one another. Defects in design will be present in all the articles manufactured according to the same design; defects in manufacture will be present only sporadically and randomly. It is the purpose of quality control and inspection to eliminate or at least reduce the frequency of defects in manufacture, but, as I said, defects in design are present by intention.

The economic behavior of producers and consumers with respect to these two kinds of defects is likely to differ. Defects of manufacture would not exist at all in a world in which information was free, for then if an article were produced that was defective in some respect, however recondite, the exact nature of the defect would be known to everyone who handled the article from the manufacturer to the ultimate purchaser. There would be no need for warranties in that world. Defective articles, if they were sold at all, would be sold at a discount, just as in the real world pottery seconds and defective soft goods now are identified as such and sold. If a purchaser bought a defective article because its price was cheap and subsequently suffered loss or injury as a result of the defect, the affair would have an entirely different cast from what it has in the real world, where the purchaser often has no practical way of knowing what the article he has purchased is like inside. At any rate, if we argue from the proposed definition of products liability, a defective article known to be such must necessarily live up to its own specifications and therefore cannot have any variation from specifications which would expose anyone, either manufacturer or purchaser, to products liability. Products liability caused by manufacturing defects could not arise in a world in which information is free.

The situation of design defects in a world of free information is slightly more complicated. Design defects I take to be of two sorts: some are purely inadvertent and some arise from attempts to reduce manufacturing costs. The inadvertent defects arise as when a bolt that could be placed in any number of places is located at a spot that tends to be damp in humid weather, leading to premature rusting and failure. Such ill fortune is common in every complicated apparatus. It is the cause of the change-orders that go out several times a day at any large automobile plant, moving the locations of the small attachments, changing bolts to welds and welds to bolts, as experience accumulates in each model year. Whether this kind of defect would 
occur in a world in which information was free depends upon how far you want to push the concept of free information.

The phrase "free information" is susceptible of two possible interpretations. The less interesting interpretation, which we can call free information in the wide sense, means that anyone can obtain freely, and therefore does obtain, full information about how an article will operate under the various conditions that it may be expected to encounter. In a world in which information was free in this sense, engineering would be vastly cheaper and better than it is in our world. In particular, the inadvertent defects in design would simply not occur because engineers would be able to foresee all the peculiar stresses and exposures that were going to beset the equipment that they were designing. All those change-orders would be unnecessary in that same world where everyone could foresee without effort the performance of various articles of manufacture. They would not be a source of products liability.

The defects that are permitted to remain in the interest of economy would have a significance entirely different from what they have in our world. For every purchaser would know precisely what he was buying and how it was going to perform. Articles designed to low quality standards would sell at an appropriate discount from higher quality articles. They could not in fact deviate from the specifications expected of them, for expectations could not be in error and therefore no products liability as I have chosen to define the concept could occur. But even waiving the niceties of formal logic, someone in that world who had purchased an inferior article at an appropriately reduced price could hardly claim indemnification if the article should fail to perform up to high quality standards, even at a critical juncture. In short, the concept of products liability would hardly be applicable in a world where information in the wide sense was free, and therefore we cannot derive any conclusions about products liability in our world by contemplating that much more perfect and congenial environment. The only conclusion we could validly come to would be that products liability does not exist.

The other possible interpretation of free information is that complete information about the specifications of articles is freely and costlessly available. This is not so very different from our world, at least as far as producers' goods go. In these circumstances, inadvertent defects of design could certainly occur and therefore there would be a risk that would have to be borne by somebody every time the design of an article was changed in any respect, no matter how small and insignificant it might have appeared to be. This risk would give 
rise to products liability and the issue of who should bear it would certainly be present. In this world also, however, the significance of defects introduced for economy's sake would be substantially different from the significance of those defects in our world, for every purchaser would of course be on notice that they are present. Under those circumstances, articles manufactured to lower specifications would sell at comparatively low prices just as if there were free information in the wider sense. And the man who accepted an article because it was comparatively cheap would thereby be accepting also the fact that this cheap article would conform to the specifications of its quality class, although not to the specifications of the most deluxe quality in its commodity class. Having saved money by accepting drum brakes, he could not expect indemnification if he experienced an accident that only disk brakes could avert. So, no issue of products liability could arise by reason of economical defects in design in a world of perfect and free information, even in the restricted sense.

I summarize this long excursus into the methodology of simplifying assumptions by concluding that no questions of products liability could arise in a world where information in the wide sense was free, and, in a world where information in the narrower sense was free, they could arise only in the restricted case of inadvertent defects of design. On either interpretation of the assumptions, the significance and the occurrence of products liability would be so wildly different from what they are in the real world that the assumptions are hardly a first approximation to the actual problem that confronts us at this meeting. The problem of products liability arises because we live in a world in which it is costly to obtain full, or even adequate, information about the products we use. We cannot abstract from these costs without changing the problem in an essential manner.

I have to call attention to another pitfall of economic reasoning. Virtually all economists, Professor McKean and I among them, are addicted to thinking about a world in which markets are perfectly competitive. Practically all of our beautiful theorems about the automatic adjustment of the economic mechanism and the attainment of a Pareto efficient allocation of resources invoke sooner or later the assumption that markets are predominantly competitive in the technical sense in which we economists love that word. In this sense, the word "competitive" means that economic transactions are impersonal, arm's-length transactions. That is, it means that the purchaser of a commodity does not care whom he buys it from and that as far as he is concerned, any unit of the commodity is as satisfactory as any other unit. When competition is perfect there are no brands, not even 
any name plates, and producers do not sign their products in any manner whatsoever.

In this connection, it pays to think of fresh apples as a pertinent example because fresh apples are, I believe, a competitive commodity in the economist's sense, and furthermore, one can suffer grave injury as a result of eating fresh apples because apple growers are in the habit of spraying their products with arsenic and arsenic is bad for people. Now suppose that someone were to become seriously ill as a result of eating fresh apples that have been grown by an overenthusiastic or careless apple grower. How would the doctrine of products liability under its most stringent interpretation apply? In the first place, it would be very difficult, if not impossible, to trace the provenance of such unbranded merchandise; it would be very unlikely for anyone to know where the offending apple or apples had come from. The law, no matter how it read, could afford the consumer no recourse. And suppose we were still living under the older doctrine by which the consumer had to bear the risks of products liability. Professor McKean has argued that consumers could protect themselves by avoiding the products of producers whose output had been found to be particularly dangerous or otherwise unsatisfactory. But in a competitive market consumers cannot do this. They cannot know whose products have been found to be dangerous, and even if they were to know this, they cannot know whose products they are buying at any moment. Or, if they can find out both of these things, then the market is no longer competitive, products are in effect branded, and all the complicated considerations which cause branded products and their imperfect markets not to conform to the simple and dandy theorems of economic optimization come into the picture. Neither Professor McKean nor I can have it both ways. We cannot argue that economic markets are perfect and therefore if left to themselves will lead to Pareto efficient organizations of economic effort, and at the same time that producers will bear the responsibility for their past indiscretions.

I therefore find it not a bit surprising that the doctrine of "privity" was applied in the nineteenth century and for some time thereafter and now is falling into disrepute. Because along about the end of the nineteenth century an important change took place in the institutional relationships among producers, purveyors and consumers. The citadel of privity may not have fallen until very recently, but the decisive breach in the outer works was made long ago at a date that I do not remember; it was the date when customers began asking their grocers for a box of Uneeda Biscuits instead of for a pound of soda 
crackers. By a very skillful advertising campaign during the 1890's, the National Biscuit Company initiated a profound revolution in our economic institutions. It removed the consumer's loyalty and reliance from his retailer and attached them to the producer. The implication of that revolution is that privileges, responsibilities and obligations which formerly had belonged to the retailer were transferred to the manufacturer of the branded products. I take it that the decline of the doctrine of privity is the legal recognition of this transformation. For once it had been made, the retailer could no longer assume responsibility for the quality of his merchandise. The guarantee and the recourse were then transferred from the retailer to the manufacturer. If this remark is just, then the whole issue that we are facing today arises in a context of branded merchandise, of manufacturers who build up reputations and are interested in maintaining them, both by advertising and by maintaining the quality of their products. Then the issue cannot fruitfully be examined in the context of a world of perfect markets where anonymous producers offer their undifferentiated wares to the choice of consumers, who neither care nor know in whose shop or on whose farm the product was created.

This circumstance makes the economic analysis both more diffcult and more interesting. It means that an adequate analysis would have to inquire into the strategic considerations of the manufacturers of branded commodities. We should have to inquire into the circumstances under which it was worthwhile for such a manufacturer to follow a variety of policies. One conceivable policy is to offer low quality merchandise accompanied, perhaps, by high quality advertising and to estimate that the saving in the cost of manufacture is more than enough to compensate for the damage to his reputation from producing a few lemons or otherwise unsatisfactory articles, plus the cost of whatever indemnities he might have to pay. Another policy would be to protect his reputation and perhaps economize on his advertising and legal expenses by very careful and expensive design and quality control. Which of these two policies would be most effective from the manufacturer's point of view would depend in intriguing ways on the potency of advertising and, indeed, on the sensitivity of his reputation to the unfortunate experiences of a few disgruntled customers. The behavior that I have observed in the real world, where competition is thoroughly imperfect, is that producers regard the consequences of having their defects found out to be much more serious than the costs of any lawsuits that they may incur. This, I take it, is why the automobile companies are reluctant to recall defective 
products. They would much prefer to pay indemnities in the case of a few accidents than to have thousands of purchasers know that the company is in the habit of turning out defective products. This kind of consideration is excluded by an analysis framed in terms of perfect competition, but I believe that it is essential to an adequate economic analysis of the consequences of products liability.

To bring the point out clearly, think again of the contrasting positions of the automobile manufacturer and the apple grower. Both are in danger of producing harmful products, even when they take all ordinary care to avoid it. The consequences to the apple grower are perhaps a lawsuit if his product can be traced and liability for the consumer's losses if the law of products liability attaches the responsibility to him. The consequences to an automobile manufacturer are damage to his reputation, whether or not the law places responsibility upon him, and as Professor McKean emphasized at several points in his argument, this is at least a partial deterrent to lightheartedly distributing defective merchandise. This deterrent, however, is effective only in the imperfectly competitive cases to which many of the other arguments put forth by Professor McKean do not apply.

The economic consequences of different social policies with respect to products liability in a world of imperfect markets remain an open question so far as my knowledge goes-an open and an intriguing question.

I have one further warning to utter. At several points in his paper, Professor McKean reiterates that part of the economist's creed that has to do with the law of demand. This is the part of the creed that reads: I believe with a perfect faith that people will buy less of a commodity if its price goes up and more of it if its price falls. Of course, I subscribe to this belief wholeheartedly, and of course, Professor McKean, for his part, is just as aware as I am of the few unimportant exceptions to it. My warning is that this undoubted doctrine is largely irrelevant to predicting the effects of changing the law of products liability. What is at issue in products liability is not the psychology of responses to price changes, but the psychology of responses to changes in the penalties that will be incurred in very remote contingencies. I do not question that people will eat more apples if the price falls. I do question that they will eat more apples or wash them less carefully if the Northwest Apple Growers Association should undertake to indemnify all people who suffer arsenic poisoning from eating apples. Businessmen appear to believe that the effect of such an announcement would be, if anything, to inhibit the consumption of apples by calling attention to the risks entailed. This does not contradict the 
law of demand, and, for all I know, may be a correct appraisal. It does not seem plausible to me that anyone without a suicidal bent, who is tempted by a succulent unwashed apple, would say to himself, "The chances that it will make me sick are very small, and besides, if it does so, the law of products liability is there to console my heirs and assigns."

Nor do I question the willingness of people to assume risks in order to make or to save money. I, myself, have driven for months on worn tires, trusting to the gods who protect practicing economists that no emergency would arise. The psychology of risk assumption appears to be complicated and has a small literature, most of it due to Thomas Schelling. It appears that people react very differently to two risks of the same actuarial value, in one of which there is a high probability of a small loss and in the other a very small probability of a large loss. Where there is a substantial probability of small or moderate losses, people act much as Professor McKean says. For example, the effect of widespread automobile insurance is undoubtedly to induce people to drive more frequently and with less care than if they were unprotected against possible losses. This is a case, of course, in which there is a high probability of a relatively small loss-I presume that few readers have not been involved in at least a minor automobile accident in the last two or three years.

But there appears to be a threshold beyond which people's reactions change, because even sophisticated minds find it impossible to envisage or appreciate contingencies with very low probabilities of occurrence. People assume risks of one in ten thousand as nonchalantly as they assume those of one in a hundred thousand; the difference is psychologically imperceptible. Aircraft accidents do not appear to have any effect on air travel, except very sporadically, immediately after a well-publicized mishap. I do not go so far as to make a positive assertion that a change in the doctrine of products liability will have no effect on the willingness of people to use hazardous products or on the care with which they use them. But I will say that Professor McKean is on unsafe ground when he asserts that the law of demand is applicable to such behavior. That is an empirical question, not a logical consequence of the law.

I am afraid that you have to conclude from my discussion that if you ask two economists any question, you will get two different answers or at best one answer and a dissent. 